of $40-75 \mathrm{mg} . / \mathrm{g}$. of wet weight. These reserves all have a special function and value to the newborn animal. G. S. Dawes and his colleagues, ${ }^{7}$ for example, have shown by years of patient work that the survival time of an asphyxiated newborn animal probably depends on the amount of glycogen available in the heart, and they have shown that the time can be raised by infusions of glucose to supplement the glycogen and of sodium carbonate to counteract the fall in $p H$ due to anaerobic breakdown of the glycogen to lactic acid. Their work is interesting experimental justification for the use of glucose and bicarbonate infusions in the treatment of infantile respiratory distress, ${ }^{8}$ some aspects of which were discussed recently in these columns. ${ }^{9}$ The glycogen in the skeletal muscles is part of the newborn animal's protection against cold, and it disappears much more rapidly in chilled newborn animals than in those kept in warm surroundings. ${ }^{10}$ The glycogen in the liver is a more general reserve and is broken down to supply glucose to the plasma to be used by any of the tissues which are in need of it. The newborn animal may possibly draw upon it to supplement the lactose in its mother's milk, which in some species-and among them the rat -contains very little. ${ }^{11}$ The extent to which the liver may store glycogen has been shown by D. S. Parsons and G. D. V. Van Rossum, ${ }^{12}$ who calculated that in the rat liver the glycogen rose from nothing to more than $40 \%$ of the total dry solids during the last four days of gestation and fell again to $5 \%$ in the next 24 hours. The interest of this work would be enhanced by taking into account the weights of all the organs involved and then calculating the total amounts of glycogen broken down during these critical hours just after birth.

In the present issue of the B.M.F. H. J. Shelley publishes a paper on the carbohydrate reserves of the newborn baby (page 273). The work must have had its disappointments, for a survey of the cases shows how impossible it has been to obtain material to analyse from an entirely normal newborn baby. There is, however, no doubt at all that the human baby falls into line with other newborn mammals in having considerable reserves of glycogen in its liver, muscles, and heart, and they must make a material difference to its chances of survival. These reserves are sometimes not enough, for it is well known now that hypoglycaemia, sometimes accentuated by cold, ${ }^{13}$ is one of the dangers threatening the newborn infant ${ }^{14-16}$ particularly one that has been undernourished during the latter part of gestation. A problem for the future is to find out more about how the reserves of fat in the human infant are related functionally with the reserves of carbohydrate. ${ }^{17}$

\section{Epidemic Keratoconjunctivitis}

In 1889 two Austrian ophthalmologists described an unusual form of acute conjunctivitis-superficial keratitis with subepithelial corneal opacities. The condition was termed nummular keratitis, superficial punctate keratitis, and by a variety of other names. ${ }^{2}$ During the next 40 years the disease was recognized in sporadic and epidemic form in many parts of the world, but did not attract much attention until the second world war. In the summer of 1941 an epidemic developed in the naval shipyards of Pearl Harbour and San Francisco and spread to many towns in California. Several thousand people, including many workers in the shipyards, were affected. M. J. Hogan and J. W. Crawford ${ }^{3}$ in a detailed description of these cases chose the term " epidemic keratoconjunctivitis" (E.K.C.). Further outbreaks were reported in many parts of North America in the following year and again in 1947-8. It was noticed at the time that the disease appeared to be limited to two groups-first, workers in shipyards (hence the term "shipyard eye") and the heavy metal industry ; secondly, ophthalmologists, staff, and patients attending eye hospitals and clinics. Few cases were reported in contacts or in the general population.

That a virus was the cause of E.K.C. had long been suspected on indirect evidence in that the disease was clearly infectious, no bacterial pathogen could be isolated, and the inflammatory response was predominantly mononuclear. In 1955 E. Jawetz and his colleagues ${ }^{4}$ isolated an adenovirus type 8 from conjunctival scrapings. Type 8 is the only serological type of adenovirus that has consistently been isolated from cases of E.K.C., whereas other types have been recovered from cases of acute follicular conjunctivitis without corneal involvement.

Virological studies have helped to unravel some of the mysteries of the epidemiology of this disease. ${ }^{5}$ In Western countries subclinical infection is rare; for example, in the U.S.A. only $5 \%$ of the adults have antibody to this particular strain of adenovirus. Thus in the West the majority of adults are susceptible to the type 8 strain. Clinical infection is limited to the eye, which seems to be the portal of entry and the main target organ. In the East subclinical infection is common. Serological studies have shown that $30 \%$ of adults in Japan have antibody and $60 \%$ in Taiwan. In Japan E.K.C. is not an occupational disease but a common childhood infection which is often accompanied by a systemic illness with fever, respiratory symptoms, and a pseudomembranous conjunctivitis. It has also been shown that very small amounts of infectious virus are produced either in the infected eye or experimentally in cell cultures. ${ }^{6}$ These factors account for the way in which infection spreads in eye clinics by direct transfer of virus from patient to patient as a result of manipulation of the patient's eyelids, and also for the lack of spread among contacts.

Two outbreaks recently reported emphasize these points. ${ }^{78}$ An outbreak of E.K.C. developed in schoolchildren in a desert community in California during a seasonal outbreak of " pink eye." A few cases also occurred in family contacts, crossinfection probably being facilitated by the copious exudate from secondary bacterial infection. ${ }^{7}$ At the same time an outbreak occurred among patients attending the physician looking after this community. Twenty-seven patients and the physician were diagnosed by the typical history, presence of subepithelial corneal opacities, and antibody to type 8 virus. The initial cases occurred in children from the local school ; the physician became infected, and then a succession of patients in a cycle of cross-infection. It was of significance that none of the children attending for ear-nose-and-throat examination became infected, whereas the attack-rate in those attending for eye complaints was $21 \%$. Of the various ophthalmic procedures to which the patient was subjected, tonometry and instillation of therapeutic drops carried the

\footnotetext{
1 Von Sttelwag, K., Wien. klin. Wschr., 1889, 2, 613

2 Fuchs, E., ibid., 1889, $2,837$.

s Hogan, M. J., and Crawford, J. W., Amer. F. Ophthal., 1942, 25, 1059

- Jawetz, E., Kimura, S., Nicholas, A. N., Thygeson, P., and Hanna, L., Science, 1955, 122,1190

- Jawetz, E., Brit. med. F., 1959, 1, 873.

27 Hanna, L., Nicholas, A., and Hoyt, R., Amer. f. Hyg., 1958, 67, 276.

7 Dawson, C., and Darrell, R., New Engl. F. Med., 1963, 268, 1031.
} 
highest risk, the attack rates being $74 \%$ and $48 \%$ respectively. The one factor common to all procedures was manipulation of the patient's eyelids by the doctor.

Recognition of the epidemiological features of E.K.C. should help to control spread of infection. Careful attention should be paid to asepsis and thorough washing of the hands before and after treatment.

\section{Drug Evaluation}

Few people are prepared to contest the necessity for careful toxicological and clinical testing of new drugs before they reach the stage of commercial distribution, and the Committee on the Safety of Drugs under the chairmanship of Sir Derrick Dunlop now exists to make sure that this is done. However, the setting up of the Committee has drawn attention to certain difficulties which are likely to be encountered. It is clear that such testing and evaluation is by no means a simple matter and may indeed be found to require greater facilities than are at present available.

These practical problems were the subject of a symposium on the evaluation of drugs organized by the Association of Medical Advisers in the Pharmaceutical Industry at the Royal Society of Medicine on 22 January. The meeting, which was under the chairmanship of Sir Derrick Dunlop, discussed both the toxicological and clinical aspects of drug testing. Dr. J. M. Barnes, of the M.R.C. Toxicology Research Unit at Carshalton, emphasized that it was unrealistic to imagine that animal tests could ever give an absolute guarantee of safety ; all useful drugs, being biologically active, were liable to cause dangerous side-effects on occasions. Animals differed greatly in their reaction to drugs according to their species and were of little help in the evaluation of subjective effects. This view was supported and amplified by Dr. G. E. Paget, the research director of Smith, Kline, and French, who suggested that there was a danger of toxicity tests becoming a ritual, with their true purpose and limitations largely forgotten. He believed that, apart from the development of tumours, any pathological damage in animals should be manifest at necropsy after a few months, and that this length of administration was long enough for detection of most chronic forms of toxicity. As to teratogenicity, he said that teratogenic changes in animals did not necessarily correlate with those in man-a problem discussed last week in these columns. $^{1}$ Toxicity studies in general could be no more than the basis of an informed guess about probable safety.

The position of clinical pharmacology was discussed by Professor A. G. Macgregor, of Aberdeen, and Dr. K. Green, of I.C.I. Professor Macgregor reminded the audience that the conception of therapeutics as an exact science was relatively new, and even now was limited to certain fields. He predicted that the terms of reference of the Committee on the Safety of Drugs would demand a prodigious amount of work and documentation which would place an ever-increasing burden on the clinical pharmacologist. Dr. Green spoke of the need for co-operation between the clinical pharmacologist and industry, without which the information required by the Dunlop Committee could never be supplied.

A combined paper by Professor W. J. H. Butterfield, of Guy's Hospital, and Dr. T. B. Binns, of Glaxo Laboratories,

\footnotetext{
1 Brit. med. F., 1964, 1, 195.
}

made proposals for expanding the facilities for clinical trials. It was recognized that such experimental work required special skill and experience as well as additional facilities. Suggestions were made about the creation of research fellowships, the setting up of more academic units, and the provision of more beds. For this, money would obviously be needed, both from the Government and from industry.

The final topic of the meeting concerned the indications for withdrawal of a drug, and this was discussed by Professor Andrew Wilson, of Liverpool, and Dr. R. Powell, of Smith and Nephew. Both of the speakers emphasized the difficulty of making hard-and-fast rules on a question of this kind. It was generally agreed that the basic freedom of the doctor to prescribe what drugs he pleased should not be lightly infringed. Full information on the dangers of drugs was the most important protection against misuse. The responsibility must remain with the doctor to keep himself informed on these matters and to make up his own mind on the basis of the facts.

\section{Fluoridation Falsified}

The great toxicity of the fluoride ion to man has made many people hesitate before accepting fluoridation of the public water supply as a desirable method of preventing dental caries. But many investigations in a variety of climates have now been carried out, and none of them even suggests that any danger could result from having 1 part per million in drinking-water. The medical and dental professions in Great Britain have expressed through the Ministry of Health, the Medical Research Council, the British Medical Association, the British Dental Association, and other organizations their approval of fluoridation as a public health measure. But one of the doubts that has lingered in the minds of some housewives (and their husbands) is whether boiling away water in cooking will lead to undesirable concentration of fluoride. Consequently the Ministry of Health sought advice on whether harm could arise in this way, and the answer was that it could not. The Chief Medical Officer (Sir George Godber) therefore sent a circular ${ }^{1}$ out to doctors a few weeks ago informing them that the safety factor in 1 part per million " is such that a person would come to no harm from consistently consuming fluoridated water which had undergone prolonged boiling, or foods prepared with fluoridated water which had undergone prolonged cooking."

In the same circular he drew attention to a letter ${ }^{2}$ published in the B.M.F. last October whose authors reported that quantities of sodium fluoride equivalent to those recommended for use in drinking-water had been found experimentally to inhibit the growth of mammalian cells. A subsequent correspondent $^{3}$ showed the experiments did not provide valid evidence that any harm would come from the drinking of water containing fluoride at the recommended level. Yet opponents of fluoridation are using the experimental data to pretend that they do. ${ }^{4}$ Passion has entered into the controversy over fluoridation because it is a measure that restricts the liberty of the individual, and none can doubt that that is worth caring about deeply. All the more inexcusable, therefore, is misrepresentation of the facts.

\footnotetext{
C.M.O. $14 / 63$.

2 Berry, R. J., and Trillwood, W., Brit. med. F., 1963, 2, 1064

Jenkins, G. N., ibid., 1963, 2, 1340.

See letter from Dr. C. G. Learoyd at p. 309.
} 